\title{
Organizational Silence in State-Owned Enterprises: Intermediary Role of the Perceptions of Organizational Politics
}

\author{
Ting Liang, Ying Wang \\ School of Government, Beijing Normal University, Beijing, China \\ Email: liangting_2013mpm@mail.bnu.edu.cn
}

Received 22 April 2016; accepted 23 May 2016; published 26 May 2016

Copyright (C) 2016 by authors and Scientific Research Publishing Inc.

This work is licensed under the Creative Commons Attribution International License (CC BY). http://creativecommons.org/licenses/by/4.0/

c) (7) Open Access

\begin{abstract}
This paper aims to explore how the employees' organizational silence and perception of organizational politics play an intermediary role in the process of generating the organizational silence in the state-owned enterprises with specific organizational climate and environment. Using 563 samples from state-owned enterprises, a linear structure equation model (SEM) is developed to examine the relationship. The research results show that the leader-member exchange has significant negative correlation with organizational silence and that the leader-member exchange has significant negative correlation with perception of organizational politics. In addition, the perception of organizational politics partially plays an intermediary role in the formation mechanism of organizational silence. Finally, the countermeasures and proposals are put forward to reduce the organizational silence of employees in the state-owned enterprises.
\end{abstract}

\section{Keywords}

Organizational Silence, Perception of Organizational Politics, Leader-Member Exchange

\section{Introduction}

Organizational silence is a kind of collective phenomenon existing in the organization, which refers to the behavior of employees to retain their views on potential problems in organization [1] [2]. Except that the pro-social silence has positive effect, the organizational silence negatively affects the organization and employees in different degree. Organizational silence will allow employees to feel unimportant, lost control and cause cognitive dissonance [3], so they show lower motivation, satisfaction, and commitment and performance level, possibly having a significant impact on organizational decision in the process of changing. One of the factors causing the 
collapse of Enron as an energy giant is that its employees always keep silent in face of the problems existing in the corporation, which ultimately threatens the organization's basic survival.

In reality, the organizational silence is very common. According to the survey of Frances on full-time employees in consulting, finance, media, pharmacy and advertising industries in America, 85\% of respondents did not represent their ideas to superiors at least once even if they are very important. In China, due to the socialized influence of traditional "Confucian" culture and the doctrine of the mean on employees, the organizational silence is more common [4].

At present, the operating state-owned enterprises in China have the total asset of nearly 8 trillion yuan. The number of state-owned enterprises (including state holding enterprises) is more than 150,000; the state-owned economy almost exists in all industries. In 2013, the total asset of state-owned enterprises all over the country was 104.1 trillion yuan, with an increase of $16.3 \%$, accounting for about $23 \%$ of all the assets. The state-owned enterprises undertake the responsibilities of national economic management tasks, so in management mode, they are similar to administrative organizations [5]. The state-owned enterprises have special management style and culture, which provide special background for us to study the organizational silence [6]. Our focus is on organizational silence behavior of employees in state-owned enterprises with special management style and organizational climate and its formation process. This study has great significant in reducing organizational silence of employees in the state-owned enterprises and improving the performance and competitiveness of enterprises.

This paper focuses on the formation process of organizational silence of employees in the state owned enterprises. In this paper, it is assumed that the leading factor has a direct impact on organizational silence, while the perception of organizational politics plays an intermediary role in the formation of individual organizational silence. Based on the samples of 563 employees in the state owned enterprises, the structural equation model is used to verify and analyze the hypothesis in this paper. Finally, the countermeasures and proposals are put forward to reduce the organizational silence of employees in the state-owned enterprises.

\section{Literature Review and Theoretical Hypothesis}

The leader-member exchange (LMX) refers to the relationship with different degrees of intimacy formed between the leadership and staff [7]. According to social exchange theory, the high-quality leader-member exchange relationship means that the employees' risks in putting forward opinions and suggestions are less than earnings, hence encouraging the staff to express their views and reduce employees' silence behavior [8]. On the contrary, the employees in the low-quality leader-member exchange are excluded from the "circle" by the superiors, and the exchange between two sides is only limited to the requirements of the employment contract; so the resources and attention obtained by such an enterprise are relatively small and the silence degree is relatively high.

In Morrison's view, the managers' inherent concept is the root of causing the silence of employees. This concept can be classified into three categories: the employees are selfish and untrustworthy; the managers understand important problems in organizations best and the harmony and consistency are embodiment of healthy organization. Because of the existence of these inherent ideas, the organization uses the centralized decision-making method and it lacks the feedback mechanism of upstream information. Thus, in the organization, the safe psychological atmosphere cannot be formed effectively, resulting in the formation of quiet atmosphere in the organization.

Some empirical studies have indicated that, the leader-member exchange quality is positively correlated with positive behavior of the individual, but it is negatively correlated with negative behavior of individual. For example, after the study on the resignation behavior of 499 managers in catering industry, Burris found that the high-quality leader-member exchange can inspire employees to have the sense of attachment and belonging to the organization, conducting the active voice behavior. The study of Dyne showed that, the employees in the low-quality leader-member exchange relationship have lower motivation and they easily have the silence behavior. In addition, taking 302 students and 249 employees as samples, Liden verified the leader-member exchange model. He found that the employees in the high-quality leader-member exchange relationship can obtain more resources and rewards, conducting higher-level organizational citizenship behavior [9].

Therefore, these hypotheses are put forward:

H1: The leader-member exchange has significant negative correlation with organizational silence; that is, the higher the quality of the leader-member exchange is, the less the silent behavior in organizations is. 
The perception of organizational politics refers to the individual's perception of political behavior in the organizational environment [10]. It contains three meanings: 1) The reason of conducting the organizational political behavior is the pursuit of some interest; 2) after the individual finds and summarizes the reason for selfinterest behavior, he/she forms his/her perceptions of organizational politics; 3) the perception of organizational politics is a kind of individual's subjective feeling. Employees' perceptions of organizational politics can also affect their behavior, such as job involvement, job satisfaction and anxiety and resignation intention.

From the perspective of the leadership, according to the social exchange theory, the subordinates in the highquality leader-member exchange relationship will gain more trust from leaders, enhancing their job satisfaction and organizational citizenship behavior and reducing the subjective perception of organizational political behavior. The individual's relationship with superiors and colleagues has the most important influence on the perception of organizational politics. If the employee believes that the leader's behavior of communication with him/ her is based on the opportunism, his/her perception of organizational politics will increase. On the other hand, good leader-member relationship means smooth communication between the staff and superiors; thus, if the employees can obtain information on the job more clearly, the employee's perception of organizational political behavior becomes lower [11]. In addition, the quality of the leader-member exchange relationship affects their judgment on fairness, that is, the employee with good exchange relationship with the leaders has higher fair sense and has lower perception of organizational political behavior. Analyzed from the reality of China, the employees in the state-owned enterprises are deeply affected by such traditional culture as the spirit of "the scholar dies for his bosom friend" and they are willing to "repay as much as you can for even a little bit of favor you have received". When the employee feels the high-quality leader-member exchange, he/she will show higher trust to the leader and lower perception of organizational political behavior [12]. Therefore, there may exist certain degree of correlation between the leader-member exchange and perception of organizational politics.

The perception of organizational politics affects organizational climate and personal attitude toward work. The organizational political behavior can have a direct impact on organizational silence to a certain degree; moreover, it can also influence organizational silence from three aspects: individual employee, organizational member relationship and organizational culture [13]. From the individual point of view, the perception of organizational politics can trigger the employee's anxiety and withdrawal behavior at work and enhance the employees' awareness of self protection, which finally leads to the defensive silence; on the other hand, as it can reduce employees' care for the organization through affecting employees' satisfaction and enhance the staff's non-action motivation, it causes the acquiescent silence. From the point of view of the relationship between organizational members, the organizational political behavior is a kind of self-interest behavior, which has one most salient feature: individual pursuit for interest; this will inevitably reduce the level of mutual trust among the members of the organization, trigging the employees' self-protection awareness and behavior and generating the defensive silence. From the point of view of organizational culture, the organizational political behavior influences organizational silence through enhanced egoism culture. The organizational political behavior of the senior leaders easily leads to the formation and diffusion of egoism culture in the organization, reducing the employees' care for the organization and organizational interest and trigging the acquiescent silence [14]. In the conclusions of the existing empirical research, Kacmar took the organizational silence as one consequence of organization of political behavior in his study. Therefore, the more the employees perceive the organizational political behavior, the higher the degree of causing organizational silence is.

In this paper, the final hypothesis model is shown in Figure 1.

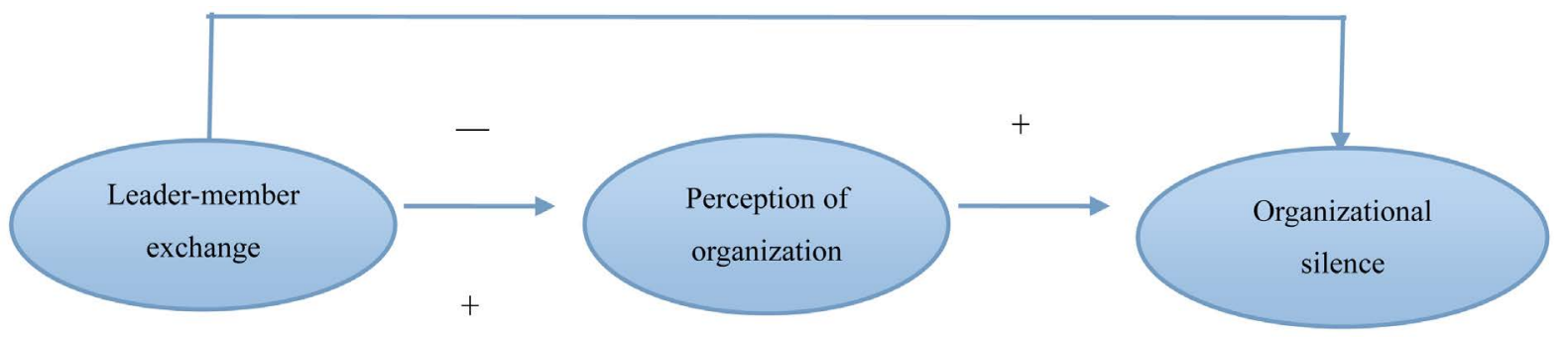

Figure 1. The final hypothesis model. Note: “+” represents positive correlation between variables; “-” represents negative correlation between variables. 


\section{Research Methods}

\subsection{Samples}

In this study, the samples were taken from the employees in six state-owned enterprises in Beijing, Hebei, Shandong and Shanxi, concerning six industries: transportation industry, mobile network industry, machinery manufacturing industry, petroleum industry, nuclear power industry and power industry. A total of 657 questionnaires were distributed, 598 questionnaires of which were recovered, including 563 valid questionnaires. Men accounted for $53.46 \%$; the persons under 30 years old accounted for $70.87 \%$; the unmarried persons accounted for $51.51 \%$; the persons with bachelor's degree accounted for $47.07 \%$; the persons with the work age of 1 - 5 years accounted for 59.93\%. The descriptive statistics of samples are shown in Table 1.

\subsection{Measurement}

The measurement of organizational silence is based on a scale with 15 items prepared by Dyne. The organizational silence can be divided into three dimensions: acquiescent silence, disregard silence and defensive silence. The measurement of perception of organizational politics is based on Ferris 's pops scale, which consists of 12 questions [15]. The measurement of leader-member exchange is based on a 12-item scale developed by Liden and Maslyn focusing on four dimensions: emotion, loyalty, dedication and professional respect. The above variables are measured through using Likert's 5-scale method.

\subsection{Common Method Bias}

In this study, the common method bias is tested, which is based on two methods [16]. First, Harman single factor test method is used. The confirmatory factor analysis is used to conduct an exploratory factor analysis of the measurement items of all variables. The common factor number is set as 1 . The results show that this factor explains $44.38 \%$ of variability. A common factor doesn't appear in the unrotated factor structure. Second, the latent error variable control method is used. In the structural equation model, the common method bias is taken as a latent variable. If, in the case of containing method bias as latent variables, the significant fitting of model is better, compared to that case without containing method bias as latent variables, the common method bias effect is verified effectively. The confirmatory factor analysis results show that, the fitting indices of one factor structure model cannot meet the essential goodness of fit, so the common method bias passes the test in this study.

\section{Analysis}

\subsection{Test on Reliability and Validity}

In terms of the measurement model, a series of confirmatory factor analysis model is designed in this paper to

\begin{tabular}{ccc} 
Table 1. Descriptive statistics of samples. & & \\
\hline Gender & Male & $53.46 \%$ \\
& Femal & $46.54 \%$ \\
Marriage & Married & $48.49 \%$ \\
& Unmarried & $51.51 \%$ \\
Educational background & High school and under & $3.55 \%$ \\
& Secondary vocational school & $29.48 \%$ \\
& Bachelor & $47.07 \%$ \\
Work experience & Master and above & $19.89 \%$ \\
& $1-3$ years & $50.27 \%$ \\
& 4 - 6 years & $29.66 \%$ \\
\hline
\end{tabular}


verify that the leader-member exchange, perception of organizational politics and organizational silence are distinguishable conception. The single factor, two factor and three factor models are compared from multiple indicators for fitting degree, and whether three concepts are independent and distinguishable is verified in the test. The results show that, all fitting indicators for three factor model reach the acceptable level, and three variables have better discrimination validity, which are all different conceptions. From the factor loading value and Cronbach's $\alpha$ coefficient in the variable measurement items, for all variables, the vast majority of factor loading values are above 0.7 , reaching the acceptable level; it indicates that the scale has better construct validity. In addition, the reliability coefficients of scales are more than 0.70 , indicating that the scale has better internal consistency reliability.

\subsection{Descriptive Statistics and Correlation Analysis}

Table 2 shows the correlation coefficients between variables. All variables are significantly correlated at the level of 0.01 . The leader-member exchange shows significant negative correlation with the perception of organizational politics, and the perception of organizational politics shows significant positive correlation with organizational silence, and the leader-member exchange shows significant negative correlation with organizational silence. This means that there may exist intermediary variable between the leader-member exchange and individual organizational silence, which may be the perception of organizational politics.

\subsection{Structural Model}

The model of adding intermediate variables in Table 3 is our focus. The difference test on the fitting chi-square values of nested models is conducted, and through the comparison between two values, two models are contrasted in terms of advantages. As Model 5 has the largest number of parameters, it is compared with Model 4. The result shows that, the significant level of $\Delta \chi^{2} / \Delta \mathrm{df}$ is 0.01 , and all the path coefficients in Model 5 are significant. So Model 5 is an acceptable model. At the same time, modification indices of the model are checked and tested. When the MI value is greater than 5 , it indicates that the variable has statistical significance; so it is advised to be incorporated into the model. As the MI value of Model 5 is less than 5, so Model 5 is taken as the finally selected model, as is shown in Figure 2.

Table 2. Matrix of variable correlation coefficients $(\mathrm{N}=563)$.

\begin{tabular}{ccc}
\hline & Leader-member exchange & Perception of organizational politics \\
\hline Leader-member exchange & 1 & 1 \\
Perception of organizational politics & $-0.333^{* *}$ & $0.596^{* *}$ \\
Organizational silence & $-0.446^{* *}$ & 1
\end{tabular}

Notes: ““*” represents significant correlation at the level of 0.01 (bilateral); “*” represents significant correlation at the level of 0.05 (bilateral).

Table 3. Fitting indicators of model structure $(\mathrm{N}=563)$.

\begin{tabular}{|c|c|c|c|c|c|c|c|c|c|}
\hline & $\chi^{2}$ & df & $\chi^{2} / \mathrm{df}$ & RMSEA & NFI & NNFI & CFI & IFI & GFI \\
\hline Model1 & 576.69 & 101 & 5.17 & 0.095 & 0.97 & 0.97 & 0.97 & 0.97 & 0.88 \\
\hline Model 2 & 583.2 & 114 & 5.12 & 0.088 & 0.97 & 0.97 & 0.98 & 0.98 & 0.89 \\
\hline Model 3 & 548.36 & 141 & 4.54 & 0.085 & 0.97 & 0.98 & 0.98 & 0.98 & 0.82 \\
\hline Model 4 & 1163.2 & 222 & 5.24 & 0.054 & 0.91 & 0.91 & 0.91 & 0.91 & 0.83 \\
\hline Model 5 & 1005.1 & 242 & 4.15 & 0.044 & 0.98 & 0.96 & 0.98 & 0.92 & 0.91 \\
\hline
\end{tabular}

Notes: Model 1 is the direct action model of the leader-member exchange on the perception of organizational politics; Model 2 is the direct action model of the leader-member exchange on the organizational silence; Model 3 is the direct action model of the perception of organizational politics on the organizational silence; in Model 4, the perception of organizational politics as an intermediate variable is added to Model 2; in Model 5, the direct path from the leader-member exchange to the organizational silence is added to Model 4. 


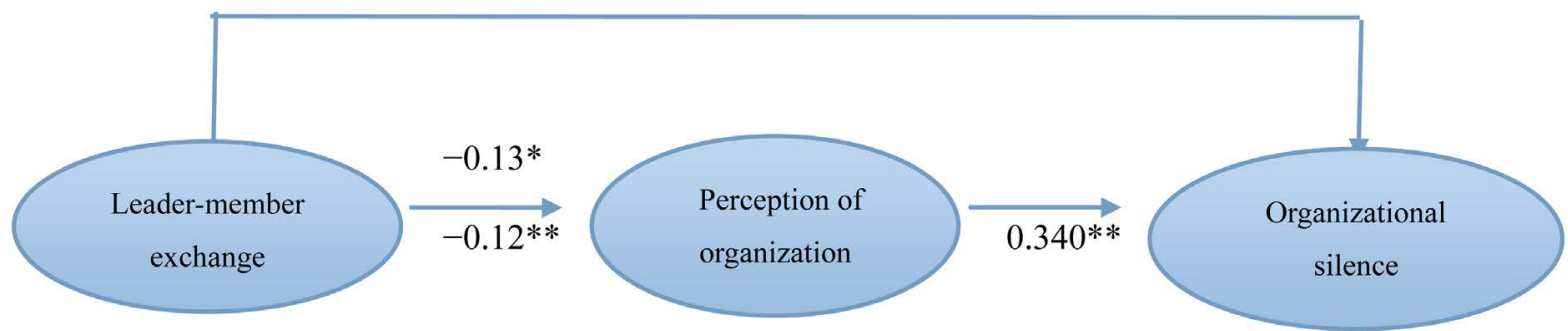

Figure 2. The finally selected model with the path coefficients. Notes: The numbers in the above figure represent the path coefficients. The numbers in brackets represent significance (if the absolute value of significance is greater than 2 , it indicates significant correlation at the level of 5\%).

\subsection{Test on Mediating Effect}

The test on the mediating effect of intermediary variables is based on a series of regression analysis [17]. The regression models are built respectively for the leader-member exchange: (1) $Y=c X+e_{1}$; (2) $M_{i}=a_{i} X+e_{2}$; (3) $Y=c_{i}^{\prime} X+b_{i} M_{i}+e_{3}$ ("Y" represent the dependent variable; " $\mathrm{X}$ " represent the independent variable; " $\mathrm{C}$ " represents the impact of $\mathrm{X}$ on $\mathrm{Y}$ in the case that there is no intermediary variable; "CI" represents the impact of $\mathrm{X}$ on Y after the intermediary variables are introduced. "e1", "e2" and "e3" represent the residual errors; "M" represents the intermediary variable). Specific procedures are as follows: Step 1: Test the regression coefficient C; if significant, continue; otherwise, stop. Step 2: Conduct Baron \& Kenny partial mediating test; that is, test Coefficient $\mathrm{a}$ and $\mathrm{b}$ in turn; if significant, it means the impact of $\mathrm{X}$ on $\mathrm{Y}$ is realized at least partially through the mediating variable; if at least one is not significant, then go to Step 4. Step 3: Conduct the third test in the Judd \& Kenny's complete mediating test; that is, test the coefficient C'; if not significant, it means the complete mediating process, that is, the impact of $\mathrm{X}$ on $\mathrm{Y}$ is realized completely through the mediating variable $\mathrm{Mi}$; if significant, it means that it is only partial mediating process, that is, the impact of $\mathrm{X}$ on $\mathrm{Y}$ is realized only partially through the mediating variable Mi. The test ends. Step 4: Conduct Soble's test; if significant, it indicates that the mediating effect of Mi is significant; otherwise, the mediating effect is not obvious. As a pretreatment stage of mediating test, all the variables are centralized after getting the mean, and then the mediating effect test is conducted for three independent variables.

The path of "the leader-member exchange-perception of organizational politics—organizational silence" is inspected. In the Equation $y=c^{\prime} x+b m+e$, " $c$ "' is -0.13 , and $p<0.000$. So, it is partial mediating effect. The independent variable has the mediating effect on the dependent variable, which is achieved not completely depending on the mediating role of intermediary variable. The leader-member exchange has direct effect on the organizational silence; the ratio of the mediating effect to the total effect is 0.689 ; the mediating effect indicates the variance variation of dependent variable is $68.77 \%$.

\section{Discussion}

\subsection{Leader-Member Exchange and Organizational Silence}

The study in this paper shows that the leader-member exchange has significant negative correlation with organizational silence, which is consistent with previous research hypotheses. The relationship between them can be explained from two aspects. Seen from the perspective of social exchange, the employees in high-quality leader-member exchange has closer relationship with the leaders, and they will have more personal interaction, emotional interaction and responsibility cognition. Their mutual interaction is based on mutual trust, loyalty and responsibility. The employees can gain more resources, training and promotion opportunities; at the same time, their mutual obligation sense becomes stronger, which encourages them to break the silence and actively put forward proposals for the enterprise. On the other hand, seen from the risk and earnings, for the employees in low-quality leader-member exchange relationship, if they put forward views, they only gain less return and face greater risk. The employees will choose silence when they are faced with crisis or problems. This is because that they are worried about negative impact on themselves brought about by the suggestions. In practice, whether the employees choose silence depends on their superiors to a greater degree. If the relationship between two sides becomes closer and even it goes beyond the scope in the contract, the employees are more willing to put forward their opinions on some problems in the organization and give their constructive comments. 


\subsection{Leader-Member Exchange and Perception of Organizational Politics}

The study in this paper shows that the leader-member exchange has significant negative correlation with perception of organizational politics, which is consistent with previous research hypotheses. Ferris pointed out in his model for the perception of organizational politics that, the relationship with the superiors and the colleagues has the most important influence on the individual perception of organizational politics [18]. If at work, the employee believes that the leader's communication with him/her is based on the opportunism, the quality of the leader-member exchange will be reduced, alienating the relationship between leaders and employees and increasing the employee's perception of organizational political behavior. Conversely, if the employee has good relationship with the superiors and becomes the leader's "insider", the perception of organizational politics will greatly be reduced. The quality of leader-member exchange determines the degree of smooth communication between the two sides. The higher the degree of interaction between the staff, superiors and colleagues is, the more the employees can clearly obtain information on the job, the lower the degree of employee's perception of organizational political behavior is. According to social exchange theory, the employees in the high-quality leader member exchange relationship will obtain more trust from the leaders, improving their job satisfaction and citizenship behavior and reducing the subjective perception of organizational political behavior. On the contrary, the employees in the low-quality leader-member relationship have lower job satisfaction, and they are more likely to produce perception of organizational politics.

\subsection{Intermediary Role of the Perception of Organizational Politics}

This study shows that, in the formation of organizational silence, the perception of organizational politics plays an intermediary role. According to the analysis of the intermediary role, the perception of organizational politics partially plays a mediating role in the relationship between the leader-member exchange and organizational silence. For the employees in the low-quality leader-member exchange relationship, they are in the economic exchange relationship with the leaders most of time; due to the lack of social exchange, they are excluded outside the "circle". Due to the lack of communication and interaction with the superiors, they gain less trust and support from the leaders, more likely to perceive the political behavior. As they are worried about their own future, they remain silent for some issues in the organization. The decrease in job satisfaction leads to the employee's indifference to organization, causing the acquiescent silence. The insecure organizational climate makes the employees have a sense of anxiety and fear, which strengthens the employees' consciousness of self protection, leading to defensive silence. This conclusion has been proved in this paper. The empirical study shows that, the perception of organizational politics plays a mediating role in the formation of organizational silence. The result is consistent with the hypothesis.

\section{Suggestions}

The state-owned enterprises are different from general enterprises as the ordinary civil subject [19]. Compared with other ownership enterprises, the state-owned enterprises, to the greatest extent, follow the traditional bureaucratic culture [20]. When the employees in the state-owned enterprises perceive more organizational political behavior, their satisfaction and psychological safety will decrease, easily leading to the silence behavior. This will cause adverse effects on the realization of organizational performance and individual development [21]. So, in this study, the proposals are put forward from the following aspects:

The good communication channels and fair atmosphere shall be established in the organization, and the organizational political behavior shall be reduced. As the organizational political behavior is the root for the employees to generate the perceptions of organizational politics, the state-owned enterprises should establish a scientific management system to improve the communicative ability of the management personnel and advocate the democratic participation of employees. The establishment of good communication channels and atmosphere can reduce the negative impact of organizational political behavior, which will help improve the employees' satisfaction and psychological safety. The atmosphere of trust enables the employees to dismiss the fears of the acts of revenge by the superiors because of their suggestions and believe that their opinions will be given attention.

From the perspective of managers, the quality of the leader-member exchange has a significant predictive effect on organizational silence. Too large power gap between the employees and leaders is too large, the non- 
open decision-making process of the organization and arbitrary decisions of leaders will increase the atmosphere of silence in the organization. On the one hand, the leaders shall respect and care for subordinates and manage to communicate with subordinates. On the other hand, the managers shall accept the employees' advices with broad mind and tolerant attitude. When making decisions, the leaders shall allow employees to participate in this process so that they can listen to the employees' views and inner voices, motivate employees to actively give some advice, reduce the employees' uncertainty and insecurity and reduce the degree of organizational silence.

\section{References}

[1] Morrison, E.W. and Milliken, F.J. (2000) Organizational Silence: A Barrier to Change and Development in a Pluralistic World. Academy of Management Review, 25, 706-725.

[2] Milliken, F.J., Morrison, E.W. and Hewlin, P.F. (2003) An Exploratory Study of Employee Silence: Issues That Employees Don’t Communicate Upward and Why. Journal of Management Studies, 40, 1453-1476. http://dx.doi.org/10.1111/1467-6486.00387

[3] Dundon, T., Wilkinson, A., Marchington, M. and Ackers, P. (2004) The Meanings and Purpose of Employee Voice. International Journal of Human Resource Management, 15, 1149-1170. http://dx.doi.org/10.1080/095851904100016773359

[4] Lee, M. (2000) The Art of Silence. Human Resource Development International, 3, 271-272. http://dx.doi.org/10.1080/13678860050128456

[5] Benson, J. and Zhu, Y. (1999) Markets, Firms and Workers in Chinese State-Owned Enterprises. Human Resource Management Journal, 9, 58-74. http://dx.doi.org/10.1111/j.1748-8583.1999.tb00210.x

[6] Whitford, A. (2002) Decentralization and Political Control of the Bureaucracy. Journal of Theoretical Politics, 14, 167-193. http://dx.doi.org/10.1177/095169280201400202

[7] Richardsa, D. and Hackettb, R. (2012) Attachment and Emotion Regulation: Compensatory Interactions and LeaderMember Exchange. The Leadership Quarterly, 23, 686-701. http://dx.doi.org/10.1016/j.leaqua.2012.03.005

[8] Detert, J.R. and Burris, E.R. (2007) Leadership Behavior and Employee Voice: Is the Door Really Open. Academy of Management Journal, 4, 869-884. http://dx.doi.org/10.5465/AMJ.2007.26279183

[9] Liden, G. and Graen, G. (1980) Generalizability of the Vertical Dyad Linkage Model of Leadership. Academy of Management Journal, 23, 451-465. http://dx.doi.org/10.2307/255511

[10] Ferris, G., Harrell-Cook, G. and Dulebohn, J.H. (2000) Organizational Politics: The Nature of the Relationship between Politics Perceptions and Political Behavior. Research in the Sociology of Organizations, 17, 89-130. http://dx.doi.org/10.1016/S0733-558X(00)17004-1

[11] Whitford, A.B. (2002) Decentralization and Political Control of the Bureaucracy. Journal of Theoretical Politics, 14, 167-193. http://dx.doi.org/10.1177/095169280201400202

[12] Hackett, R.D., Farh, J.L., Song, L.J. and Lapierre, L.M. (2003) LMX and Organizational Citizenship Behavior: Examining the Links within and across Western and Chinese Samples. In: Graen G., Ed., Dealing with Diversity: LMX Leadership-The Series, Information Age, Greenwich, CT, 1, 219-263.

[13] Dyne, L.V., Ang, S. and BoteroI, C. (2003) Conceptualizing Employee Silence and Employee Voice as Multidimensional Constructs. Journal of Management Studies, 40, 1359-1392. http://dx.doi.org/10.1111/1467-6486.00384

[14] Kacmar, K.M. and Ferris, G.R. (1991) Perceptions of Organizational Politics Scale (POPS): Development and Construct Validation. Educational\& Psychological Measurement, 51, 193-205. http://dx.doi.org/10.1177/0013164491511019

[15] Ferris, G.R. and Kacmar, K.M. (1992) Perceptions of Organizational Politics. Journal of Management, 18, 93-116. http://dx.doi.org/10.1177/014920639201800107

[16] Podsakoff, P.M., MacKenzie, S.B. and Lee, J.Y. (2003) Common Method Biases in Behavioral Research: A Critical Review of the Literature and Recommended Remedies. Journal of Applied Psychology, 5, 879-903. http://dx.doi.org/10.1037/0021-9010.88.5.879

[17] MacKinnon, D.P., Lockwood, C.M., Hoffman, J.M. and West, S.G. (2002) Sheets V.A Comparison of Methods to Test Mediation and Other Intervening Variable Effects. Psychological Methods, 1, 83-104. http://dx.doi.org/10.1037/1082-989X.7.1.83

[18] Ferris, G.R., Adams, G., Kolodinsky, R.W., Hochwarter, W.A. and Ammeter, A.P. (2002) Perceptions of Organizational Politics: Theory and Research Directions. Research in Multi Level Issues, 12, 179-254. http://dx.doi.org/10.1016/S1475-9144(02)01034-2

[19] Chang, H.-J. (2007) State-Owned Enterprise Reform. United Nations DESA, New York. 
[20] Buckley, P.J., Clegg, J. and Tan, H. (2005) Reform and Restructuring in a Chinese State-Owned Enterprise: Sinotrans in the 1990s. Management International Review Publisher, 45, 2-6.

[21] Dundon, T., Wilkinson, A., Marchington, M. and Ackers, P. (2004) The Meanings and Purpose of Employee Voice. International Journal of Human Resource Management, 15, 1149-1170.

http://dx.doi.org/10.1080/095851904100016773359 